\title{
Notícias de D. Xicote: a presença de Josué Guimarães no sistema literário da Serra Gaúcha
}

João Claudio Arendt*

Leticia Lima**

\section{Resumo}

Neste artigo, investigamos a presença de Josué Guimarães na imprensa escrita de Caxias do Sul, entre os anos 1950 e 1980, com vistas a refletir sobre a influência da literatura suprarregional na formação e na consolidação do sistema literário da Serra Gaúcha. O enfoque volta-se aos jornais A Época, Pioneiro, Diário do Nordeste e Jornal de Caxias, que fazem menções ao escritor em entrevistas, colunas sociais, listas de obras mais vendidas, simulados de vestibular e notícias sobre publicação de livros. Chama a atenção, de modo especial, a existência de colunas assinadas pelo pseudônimo D. Xicote em dois desses periódicos, no início da década de 1950.

Palavras-chave: Josué Guimarães; D. Xicote; imprensa regional; sistema literário da Serra Gaúcha.
Estranha carreira a desse hoje barbudo escritor gaúcho chamado Josué Guimarães. [...] Deixou crescer a barbam e enfim assumiu o papel de escritor que lhe estava destinado: desandou a escrever de enfiada um livro atrás do outro. [Jornal de Caxias, 24/02/1979, p. 6]

\section{Introdução}

Quando se fazem buscas sobre a trajetória pessoal de um(a) escritor(a) ou sobre a recepção de suas obras, uma série de surpresas positivas e negativas pode acontecer. $\mathrm{O}$ inesperado surge em uma gaveta com traças, em um baú perdido em algum sótão, na biblioteca impecavelmente organizada de um bibliófilo ou nas

\footnotetext{
* Professor permanente no Programa de Pós-graduação em Letras da UFES. Coeditor da Revista Contexto. Coordenador do GT História da Literatura da ANPOLL. E-mail: joaoarendt@gmail.com

** Graduada em Letras e Mestra em Letras e Cultura pela Universidade de Caxias do Sul. E-mail: 1lima4@ucs.br

Data de submissão: ago. 2021 - Data de aceite: out. 2021 http://dx.doi.org/10.5335/rdes.v17i3.12791
} 
páginas de antigos jornais de circulação municipal. Definitivamente, não há como prever onde e quando os sobressaltos aparecerão ao pesquisador.

Em relação a Josué Guimarães, foi algo dessa natureza que nos aconteceu, quando buscávamos dados sobre a presença da literatura suprarregional no sistema literário da Serra Gaúcha. Salvo engano, os primeiros registros do nome do escritor em jornais de Caxias do Sul datam do início da década de 1950, especialmente em A Época, Diário do Nordeste e Pioneiro, e, mais tarde, no Jornal de Caxias. As menções ao autor estendem-se décadas afora e aparecem em listas de obras mais vendidas da Feira do Livro de Caxias do Sul, em notícias sobre conferências e lançamento de novos livros, bem como em encartes com conteúdo de literatura para o vestibular. Ao mesmo tempo, ele aparece em contextos bastante inusitados, como, por exemplo, o de autor preferido de candidatas à Rainha da Festa Nacional da Uva.

Nessa perspectiva, objetivamos, neste trabalho, mapear os registros sobre Josué Guimarães nos referidos periódicos, com vistas a fomentar a discussão sobre a presença de literatura suprarregional no sistema literário da Serra Gaúcha, em especial de Caxias do Sul. Para tal, partimos de uma breve abordagem sobre "sistema literário regional”, seguida da discussão acerca do papel da mídia impressa na divulgação e circulação da literatura na região serrana, para, finalmente, avaliar as ressonâncias e possíveis influências do escritor sobre a literatura local.

\section{A literatura regional como sistema literário}

Considerando as discussões que já efetuamos sobre o tema e que resultaram em publicações anteriores, julgamos importante frisar, para os propósitos deste texto, que os diferentes sistemas literários constituem-se a partir de trocas literárias em diversos níveis e sentidos. Geralmente, entre os critérios utilizados para a seleção de autores que podem integrar uma história literária nacional ou estadual (esta também apodada de "regional"), estão o nascimento ou uma estada temporária que resultou na publicação de uma obra. Em outros termos, o escritor deve ter nascido, vivido ou atuado no local abrangido pelo sistema literário.

No entanto, esses critérios podem ser mais flexíveis, quando dizem respeito, por exemplo, à literatura regional. $\mathrm{O}$ pesquisador alemão Jens Stüben (2013) propõe que, para integrar uma história literária regional, a seleção das obras seja baseada nas seguintes premissas: 
- Surgiram na respectiva região (ainda que tenha sido o local de estadia acidental do autor);

- Foram elaboradas no discurso regional e permitem reconhecer relações intertextuais com traços regionais;

$\checkmark$ Originaram-se de estímulos que o autor tenha experimentado dos cenários, locais e pessoas de uma região;

- Representam uma região e têm com ela um traço temático como motivo e pano de fundo;

- Acima de tudo, tenham sido escritas para um público leitor de uma região;

- Foram publicadas em uma editora ou em um órgão de imprensa locais;

- Foram disseminadas e surtiram efeito na região (no público, na crítica literária, em outros autores) - em geral em função de sua estreita ligação temática com a região;

- Provêm de autores que tenham nascido ou crescido na região, mesmo sob circunstâncias em que nas obras ocorrem traços regionais somente por acidente, e o local de surgimento e a recepção sejam outros;

- Provêm de autores que viveram na região e foram inspirados pela paisagem, suas pessoas e cultura.
A escolha de obras - e de autores deve considerar as chamadas regionalidades internas (os aspectos temáticos) e externas ao texto literário (a produção, a publicação e a recepção), de modo a quebrar com os paradigmas tradicionais de nascimento e pertencimento de obras e autores a certos territórios. Desse modo, a noção de sistema torna-se mais dinâmica e possibilita verificar a rede de relações que a literatura estabelece entre tempos e espaços diversos.

No caso específico de Josué Guimarães, não há registros oficiais de que, afora as breves estadas documentadas pela mídia impressa, tenha morado ou publicado obras em Caxias do Sul. Também não se sabe se ele inspirou-se na paisagem ou na cultura local. Entretanto, a presença do seu nome na imprensa periódica do município, desde a década de 1950 até depois do ano da sua morte, é significativa, seja como ilustre visitante, seja como autor de obras mencionadas em listas de livros publicados ou mais vendidos na Feira do Livro, seja como autor das brevíssimas colunas satíricas assinadas por D. Xicote, nos jornais $A$ Época e Diário do Nordeste. Mesmo difícil, mas não impossível, de ser aferida, essa presença pode ter surtido efeito no público, na crítica literária e em autores locais. 


\section{O papel da imprensa periódica no sistema literário da Serra Gaúcha}

Como poderá ser visto neste trabalho, a imprensa periódica exerceu papel de relevante influência no sistema literário serrano. Especialmente no que diz respeito ao período que compõe o recorte temporal adotado nesta pesquisa, a saber, as décadas de 1950, 1960, 1970 e 1980, essa atuação da mídia impressa pode ser observada em diferentes periódicos que circulavam na região à época.

A pesquisadora Aline Brustulin Cecchin (2014), ao estudar a consolidação do sistema literário regional na Serra Gaúcha a partir do surgimento do Grupo Matrícula, em 1967, chama atenção para a existência de uma vasta bibliografia voltada à relação em geral entre imprensa e literatura. Destaca, também, que a pesquisa em periódicos constitui uma fonte rica de informações, quando o que se pretende é "investigar os meios de produção, circulação e recepção da literatura e suas relações com a imprensa" (CECCHIN, 2014, p. 44).

No que diz respeito à literatura, Cecchin (2014, p. 44) afirma que, para além de contribuir para o resgate de diferentes gêneros textuais, tais como sonetos, poemas, contos e crônicas, o trabalho com os periódicos possibilita "a leitura de determinada paisagem literá- ria, no tempo e no espaço". É justamente nessa premissa que se pauta o presente estudo, uma vez que objetiva, por meio do mapeamento de registros dos jornais A Época, Pioneiro, Diário do Nordeste e Jornal de Caxias, investigar a presença de Josué Guimarães no sistema literário serrano e, acentuadamente, na cidade de Caxias do Sul.

Historicamente, o período entre os anos finais da década de 1950 e iniciais da década de 1960 em Caxias do Sul é marcado por uma efervescência industrial e comercial. Essa movimentação, todavia, não se limita somente a esses setores, sendo também percebida no que se refere ao desenvolvimento cultural e intelectual na cidade. À época, por exemplo, podem-se destacar dois acontecimentos que chamam a atenção no campo literário, a saber, a primeira edição da Feira do Livro de Caxias do Sul, que ocorreu em janeiro de 1959, e, pouco depois, a fundação da Academia Caxiense de Letras, em $1^{\circ}$ de junho de 1962.

De acordo com Cecchin (2014), ainda no limiar dos anos sessenta, surgem o Concurso de Crônicas sobre a Festa da Uva, em 1960, e o Concurso de Redação do CTG Rincão da Lealdade, em 1962. Contudo, é na última metade dessa década que esse movimento de valorização da escrita literária, isto é, de concursos literários, ganha maior vigor na região de Caxias do Sul. Em 1966, por exemplo, 
é promovido o Concurso Literário da Semana do Exército. Em 1967, têm-se as edições dos Concurso Literário Estudantil, Concurso de Redações Sobre o Dia dos Pais e Concurso de Poesia sobre a Semana Farroupilha. E, em 1968, a promoção do Concurso de Crônicas sobre a "Feira da Ternura". Além dos concursos já citados, é também de 1967 a primeira edição do Concurso Anual de Contos, Crônicas e Poesias (hoje Concurso Anual Literário), que, em 2021, chegou a sua $55^{\mathrm{a}}$ edição.

Nesse sentido, sublinha-se a atuação dos jornais no que tange a esses concursos. De acordo com Cecchin (2014), os periódicos, além de anunciarem os concursos, também traziam notícias sobre $o$ seu andamento, o número de inscritos, os escritores participantes, as datas de divulgação dos vencedores e de entrega dos prêmios. É válido, também, ressaltar a importância desses veículos enquanto meio de circulação de textos literários, com publicações de crônicas, sonetos e poemas de diversos autores. Apenas a título de exemplo, em trabalho ${ }^{1}$ realizado no projeto de pesquisa "Uma história da leitura e da literatura na Serra Gaúcha (1897-1967)", concluímos que, somente entre os anos de 1951 e 1960, o poeta caxiense Cyro de Lavra Pinto publicou cerca de 330 poemas, e sabemos que não parou de publicar na década de 1960 .

Apesar de breve, este panorama possibilita pensar a relação entre mídia e literatura, sobretudo no que se refere à atuação de periódicos como meio de circulação e divulgação de textos literários e, consequentemente, seu papel na consolidação do sistema literário de uma região, neste caso, da Serra Gaúcha. É com vistas a esses pressupostos que passamos, na sequência, a investigar a presença de Josué Guimarães na mídia impressa de Caxias do Sul, por meio do resgate de materiais publicados nos jornais A Época, Jornal de Caxias, Pioneiro e Diário do Nordeste.

\section{As primeiras aparições de Josué Guimarães em jornais de Caxias do Sul}

Como já afirmamos, os primeiros registros documentados pela mídia impressa da presença de Josué Guimarães em Caxias do Sul datam do começo da década de 1950 e se estendem pelos anos seguintes. Inicialmente, trata-se apenas do jornalista e do vereador porto-alegrense e, a partir dos anos 1970, do escritor. É assim que, por ocasião da inauguração, em 24 de junho de 1951, de um novo aparelho teletipo na agência local de Correios e Telégrafos, Josué aparece listado, entre as autoridades presentes, como "chefe de gabinete da Secretaria do Interior", do governo do Estado do Rio Grande do Sul. Na imagem a seguir, o flagrante do momento: 
Figura 1 - Josué Guimarães em inauguração em Caxias do Sul

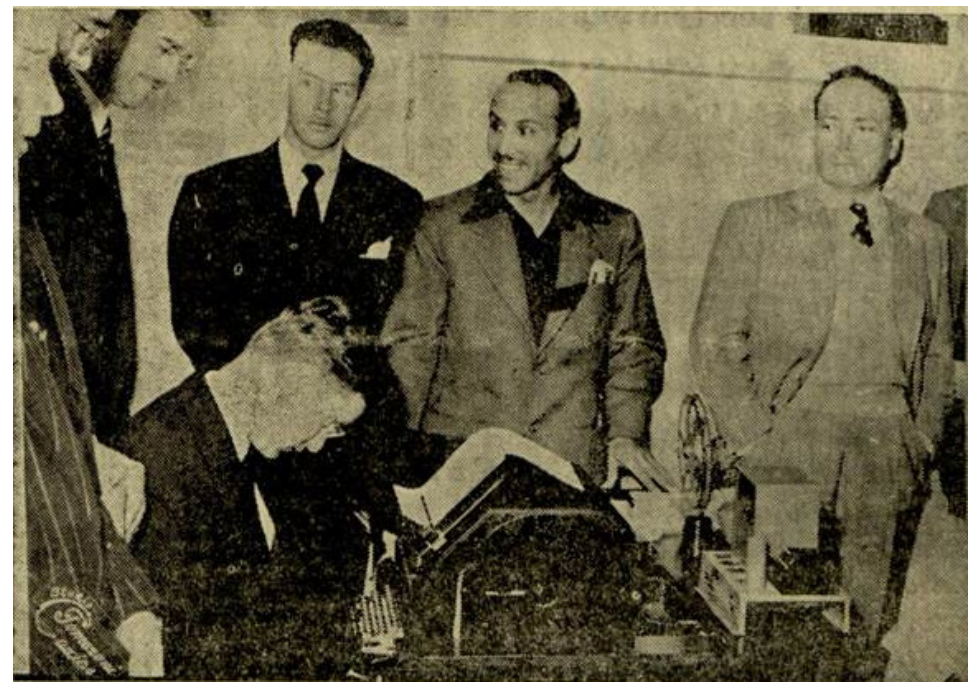

Fonte: Diário do Nordeste (26/06/1951, p. 8).

Ainda no mesmo ano, o futuro autor de $A$ ferro e fogo figuraria em matéria sobre a coroação da rainha dos esportes, evento realizado pelo Clube Juvenil de Caxias do Sul. Além de coroar a sobera- na, Josué proferiu uma "oração", a qual foi publicada, na íntegra, na edição do dia 18 de dezembro, do jornal Diário do Nordeste. Da ocasião, o jornal tornou público o seguinte registro fotográfico:

Figura 2 - Josué Guimarães coroa Rainha dos Esportes em Caxias do Sul

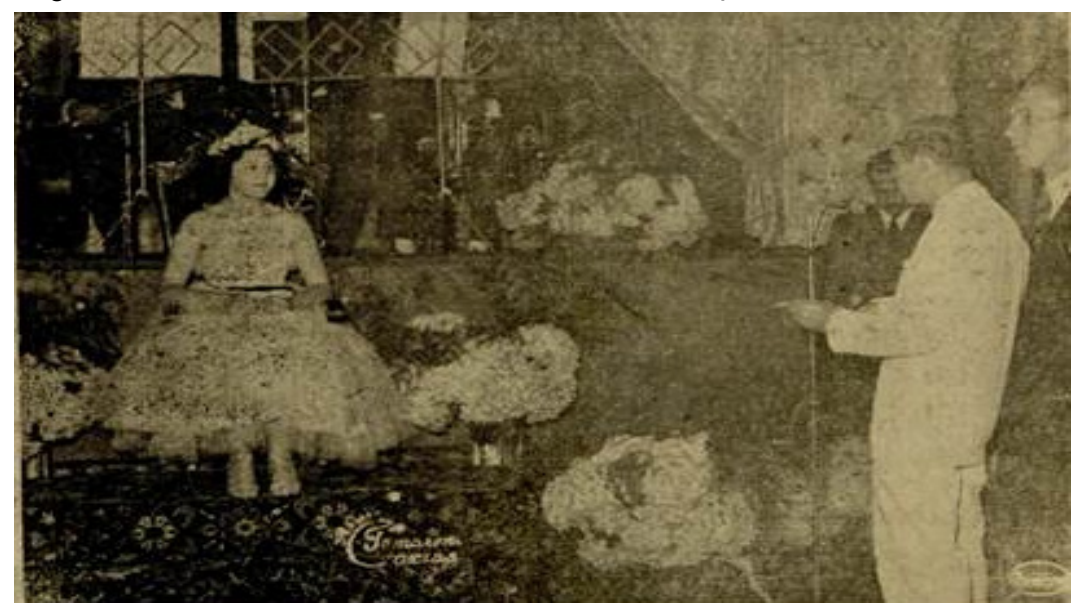

Fonte: Diário do Nordeste (18/12/1951, p. 7). 
Já em 1952, ambos os jornais Pioneiro e Diário do Nordeste noticiam a realização de uma conferência promovida pelo Conselho Municipal de Defesa da Paz, com a presença do jornalista Josué Guimarães e do escritor Jorge Amado. No dia 23 de agosto, o Pioneiro publica uma nota de reprovação ao teor de "propaganda comunista" da conferência do escritor baiano, afirmando que a "presença de inúmeros caxienses" deveu-se apenas aos "méritos incontestáveis" dos visitantes: "o primeiro como romancista e o segundo como jornalista". Veja-se a matéria na íntegra:

Figura 3 - Josué Guimarães em Conferência de Jorge Amado em Caxias do Sul

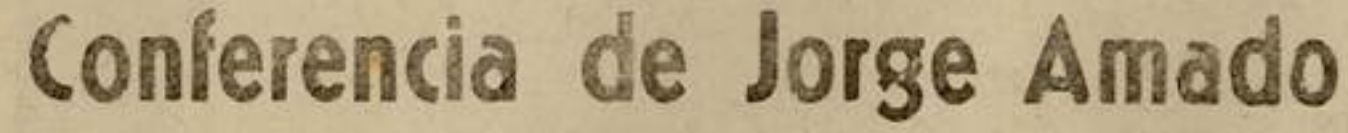

Realizou em nossa cida- Russa Socialista Soviética. Foi êste o motivo da prede o escritor Jorge Amado uma conferência que esteve muito concorrida. Foi pro movida pelo Conselho Mu- munista, em todos os sennicipal da Paz. Jorge Ama- tidos. Velada, aberta, disdo, que é uma das mais só- farçada, franca, ela existiu lidas penas do pais, pro- em todos os matizes. A nunciou uma conferência presença de inumeras pessóbre a excelência da paz, soas deu-ze apenas pelos enquanto que seu compa- méritos incontestáveis que nheiro de visita Josué Gui- possuem Jorge Amado e oradores, estabelecendo-se marães, fez um relato de Josué Guimarāes, o pri- animados debates sôbre cosuas impresões sôbre uma meiro como romancista e munismo, guerra bacteriorecente viagem á Uniāo o segundo como jornalista. lógica, ete.

Fonte: Pioneiro (23/08/1952, p. 1).

Nos anos seguintes, Josué aparece diversas vezes no jornal Pioneiro, seja na condição de jornalista, seja na de vereador. Na festa de formatura do Curso Comercial Salgado Filho, por exemplo, noticiada no dia 28 de maio de 1955 , o então vereador porto-alegrense é fotografado entregando uma medalha ao quarto colocado nos exames finais do curso, como se vê a seguir:
Figura 4 - Josué Guimarães na formatura do Curso Comercial Salgado Filho

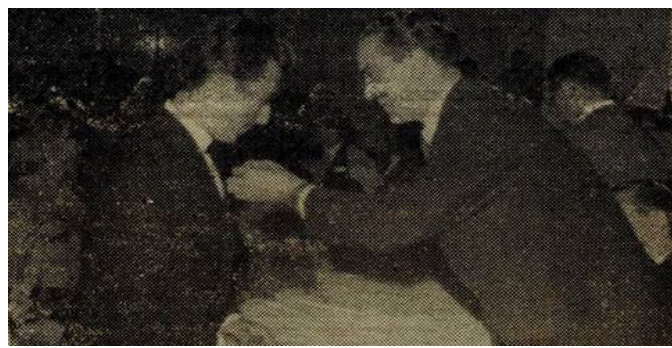

Fonte: Pioneiro (28/05/1955, p. 2).

Essas aparições de Josué Guimarães na imprensa caxiense são carregadas 
de sentido, porque documentam o seu percurso como jornalista e político fora de Porto Alegre, que era, à época, um dos seus principais espaços de atuação profissional. Ao publicar o primeiro livro, Os ladrões, em 1970, ou seja, quase vinte anos depois dos registros aqui resgatados, o autor já tinha pavimentado o caminho que haveria de percorrer como escritor. A prova definitiva disso também está documentada na imprensa caxiense, conforme será visto nas seções a seguir.

\section{Os comentários de} D. Xicote ${ }^{2}$

Em 23 de fevereiro de 1950, o jornal A Época faz o anúncio de que o jornalista Josué Guimarães, que "não é outro sinão o muito popular D. Xicote", estaria escrevendo as suas "apreciadíssimas crônicas para uma rede de jornais do interior do estado", dentre os quais figuraria o periódico em questão. De fato, dois dias depois, surgem os primeiros comentários:

Figura 5 - A Época noticia o início das publicações de D. Xicote

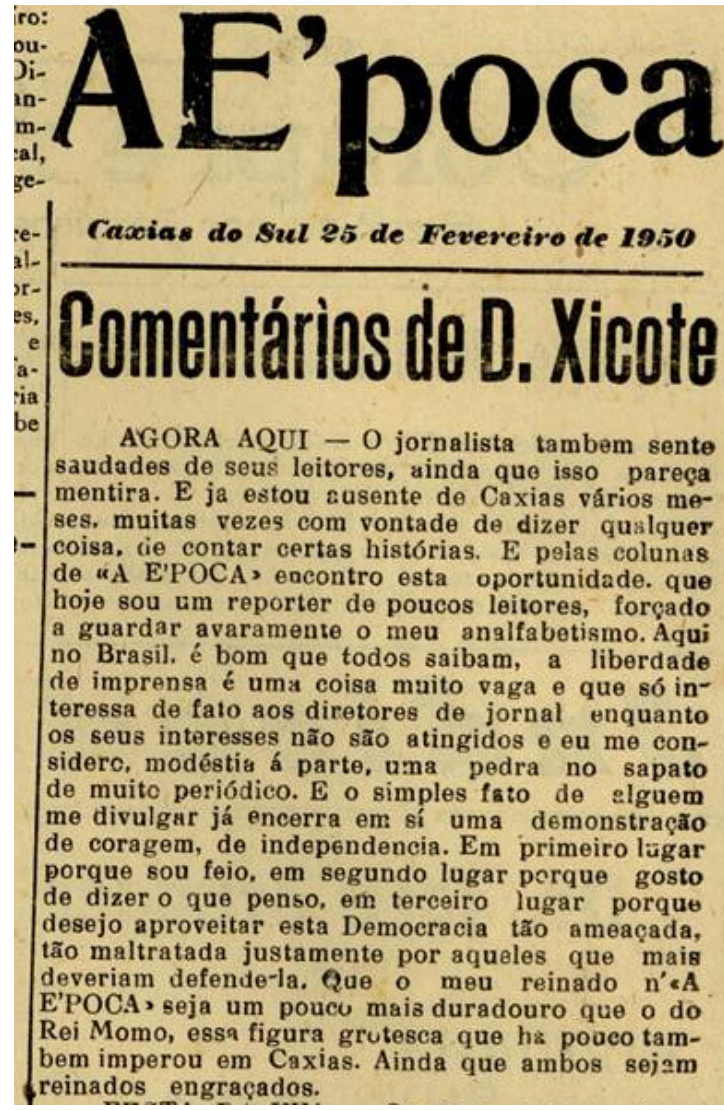

Fonte: A Época (25/02/1950, p. 8). 
Do excerto que recortamos, salta aos olhos a questão do metajornalismo. Josué Guimarães apresenta-se como um "repórter com poucos leitores", mas com muita "vontade de dizer qualquer coisa, de contar certas histórias". Na sequência, elogia a atitude corajosa do jornal por abrir espaço para os seus comentários, em razão de no Brasil a liberdade de imprensa ser "coisa muito vaga", que só interessaria aos periódicos "enquanto os seus interesses não são atingidos". Embora o jornalista encerre o tópico desejando que o seu "reinado n'A Época seja mais duradouro que o do Rei Momo", a coluna parece encerrar abruptamente dois meses depois, contabilizando apenas seis participações.

Poucos anos depois, em 13 de junho de 1953, o colunista reaparece no Diário do Nordeste, quando o jornal inaugura uma seção igualmente intitulada "Comentários de Don Xicote”, acompanhada da seguinte nota da redação:
Figura 6 - Inauguração dos Comentários de Don Xicote no Diário do Nordeste

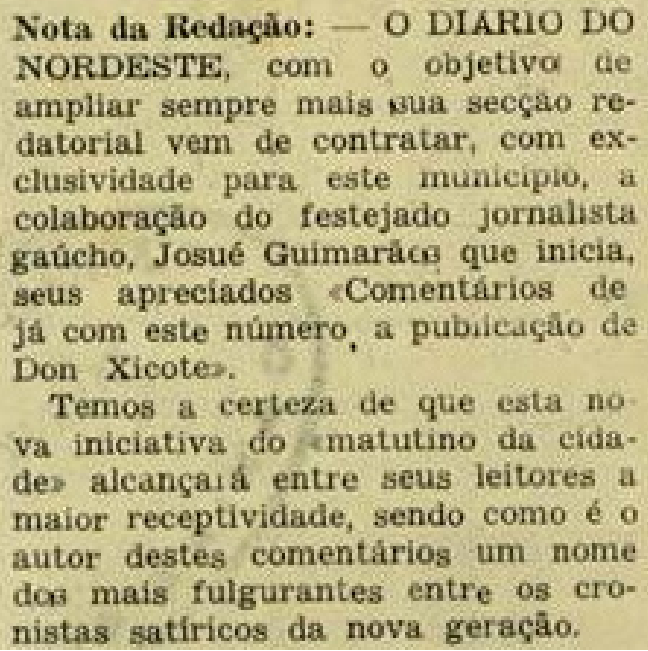

Fonte: Diário do Nordeste (13/06/1953, p. 2).

O caráter de exclusividade de conteúdo na imprensa caxiense denota o alcance e a importância do jornalismo crítico e bem-humorado de Josué Guimarães. Criado em 1944, quando era jornalista do Diário de Notícias, o pseudônimo D. Xicote parece ter feito muito sucesso junto ao público, a ponto de, inclusive, ter dado nome a um jornal fundado e mantido às próprias custas pelo autor, em 1949 (CLEMENTE, 1997, p. 14).

No período que compreende as colunas publicadas nos dois jornais, ou seja, entre 1950 e 1953, encontramos menções ao pseudônimo nas matérias ligadas a Josué e já mencionadas aqui, tais como: "A seguir, o jornalista Josué Guimarães (D. Xicote) coroou a Rainha, sendo o ato culminado com uma estrondosa salva 
de palmas" (DIÁRIO DO NORDESTE, 18/12/1951, p. 7); e "Sua Senhoria se faz acompanhar do brilhante jornalista gaúcho Josué Guimarães, o conhecido D. Xicote, que também terá a oportunidade de falar naquela reunião cultural" (DIÁRIO DO NORDESTE, 20/08/1952, p. 8). O pseudônimo já era, portanto, bem conhecido do público e imprimia ares de notoriedade ao articulista.

Essa informação também pode ser comprovada em buscas pelo pseudônimo no Pioneiro, de que se podem destacar ao menos dois registros que possibilitam refletir sobre o considerável sucesso dos comentários de D. Xicote. O primeiro deles data de 19 de agosto de 1950, em que se lê, após crítica a um possível candidato a deputado federal pela cidade de Caxias do Sul, a seguinte nota: "Mandado transcrever de A ÉPOCA DE 29-2-1950 dos Comentários de D. Xicote, por um grupo de caxienses" (PIONEIRO, 19.08.1950, p. 10).

O segundo, por sua vez, trata-se de crônica do escritor e historiador caxiense Mário Gardelin, que, sob o título de "Seleções do Dr. Moenda", narra feitos da personagem que dá nome ao texto. Na ocasião, D. Xicote é citado logo no primeiro parágrafo e sua figura é marcada pelo teor crítico característico dos comentários, conforme se pode observar no excerto a seguir:

Figura 7 - Referência a D. Xicote no Pioneiro

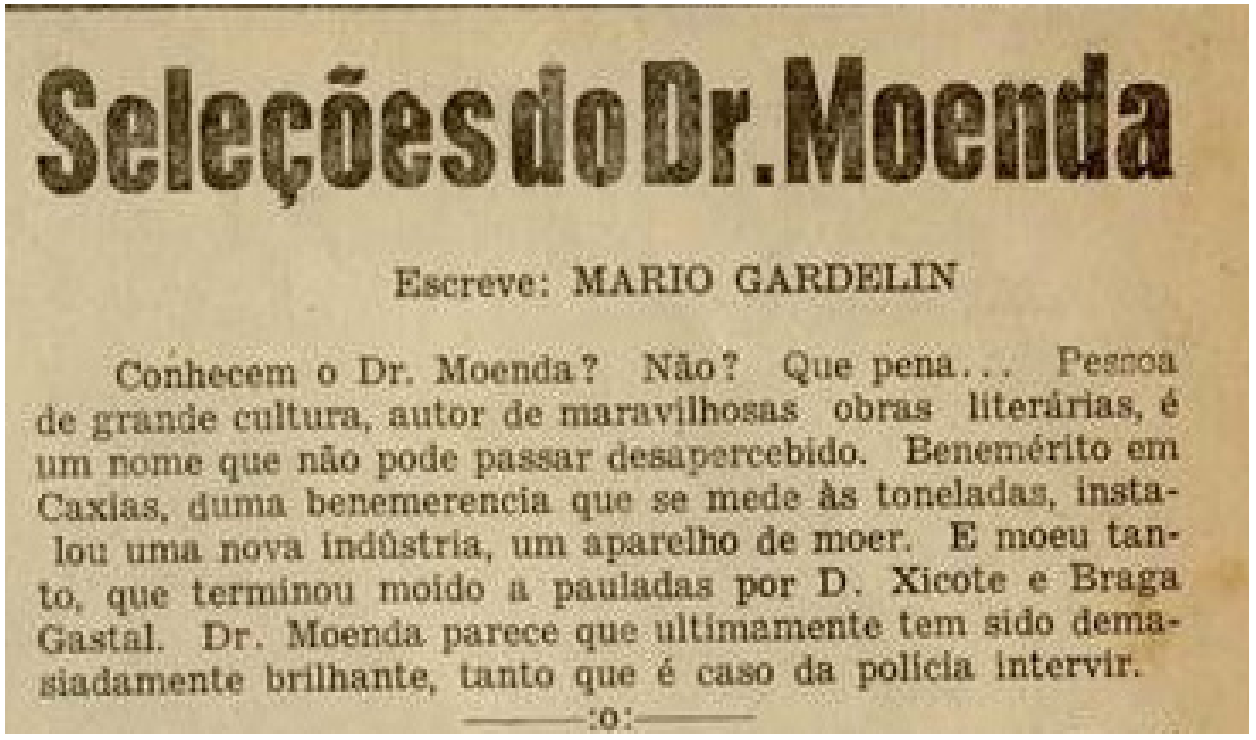

Fonte: Pioneiro (19/04/1952, p. 3). 
Ainda no caso do jornal Diário do Nordeste, os registros que encontramos documentam que a coluna estendeu-se de 13 de junho de 1953 até 04 de se- tembro daquele mesmo ano, totalizando quinze ocorrências. ${ }^{3} \mathrm{Na}$ imagem a seguir, a título de registro, é possível ter uma visão geral de uma dessas publicações:

Figura 8 - Comentários de Don Xicote no Diário do Nordeste

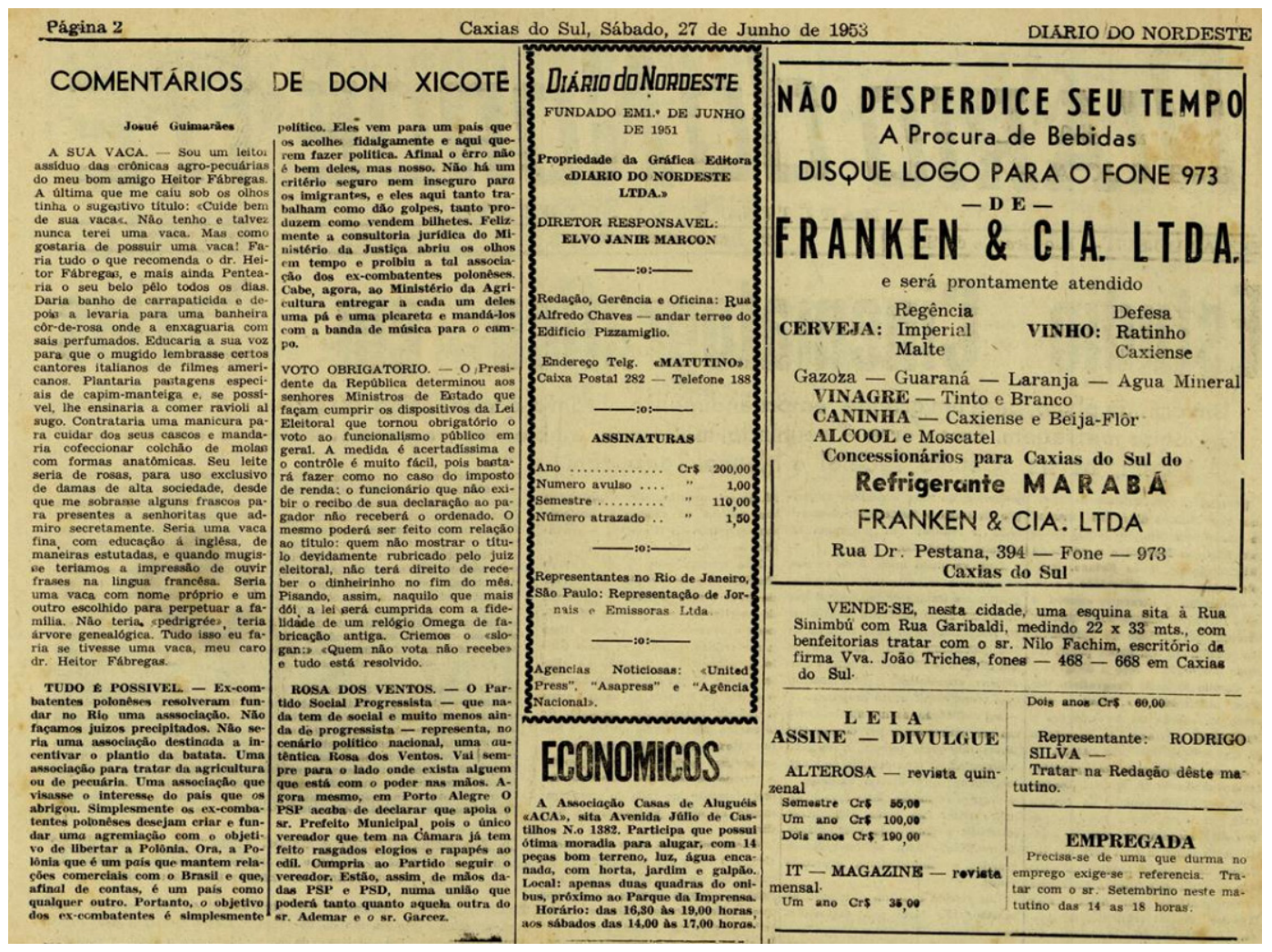

Fonte: Diário do Nordeste (27/06/1953, p. 2).

O teor dos comentários de Don Xicote, em suma, é amplo e abrange desde acontecimentos cotidianos até eventos no campo da cultura e da política. No caso do excerto em destaque, o autor discorre, de forma humorada, sobre a leitura dos livros do veterinário Heitor Fábregas, a criação de uma associação de ex-combatentes poloneses no Rio de Janeiro, o voto obrigatório do funcionalismo público e a união entre os partidos PSP e PSD, em Porto Alegre. 


\section{Feira do Livro, pré- vestibular, Festa da Uva e listas de obras}

Nas décadas de 1970 e 1980, observamos um fenômeno interessante em relação a Josué Guimarães no jornal Pioneiro. ${ }^{4}$ Trata-se da menção do nome do autor e de suas obras na programação das Feiras do Livro de Caxias do Sul e de Canela, em simulados de pré-vestibular, em listas de obras mais vendidas ou de lançamentos e até como autor preferido de candidatas à rainha da Festa da Uva. Esse aspecto merece atenção não só pelo fato de comprovar a boa inserção da obra do escritor entre o público leitor da Serra Gaúcha, mas também por sua transformação em lugar de memória. ${ }^{5}$

Em $1^{\circ}$ de novembro de 1978, o jornal publicou a lista dos autores nacionais e estrangeiros mais vendidos na IV Feira do Livro de Caxias do Sul. Entre quase 1.200 livros vendidos nos dois primeiros dias, Josué Guimarães aparece ao lado de Jorge Amado e Erico Verissimo. Segundo a matéria, o público comprador seria, em sua maioria, do sexo masculino e com menos de 30 anos de idade.

No mesmo ano, em 11 de novembro, na seção "Variedades", a obra Dona Anja, por exemplo, recebe destaque no periódico:
Figura 9 - Dona Anja no Pioneiro

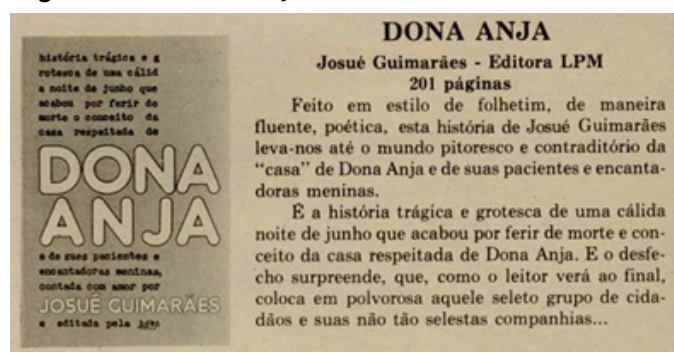

Fonte: Pioneiro (11/11/1978, p. 40).

No ano seguinte, é Cavalo cego que ganha destaque na mesma seção do jornal. $\mathrm{O}$ autor é caracterizado como "marcadamente um realista, preocupado com a história e com as grandes e pequenas convulsões sociais", e a obra, como "um livro a ser pensado, sem que o prazer da leitura fique em qualquer instância diminuído" (PIONEIRO, 24/11/1979, p. 48).

Em 11 de novembro de 1980, Josué Guimarães, por ocasião de sua passagem pela Livraria do Maneco para autografar o recém-lançado Camilo Mortágua, aparece em reportagem de página inteira do Pioneiro. Apresentado como "o escritor que mais vendeu livros na última Feira do Livro de Porto Alegre", o autor falou ao jornal sobre a concepção e a escrita do seu último romance, a sua atuação política, o ambiente para escrever, a recepção e o futuro da sua obra. Conforme se verifica em reportagem do Jornal de Caxias (17/11/1980, p. 33), Josué veio a convite da Universidade de Caxias do Sul, de modo que, antes da sessão de autógrafos, teria tido um encontro informal com estudantes da instituição. 
Além dessas notícias, chamam a atenção os simulados de pré-vestibular, que surgem nos jornais a partir da década de 1980. Na primeira aparição do autor nesse tipo de material, o enfoque recai, de forma extremamente simplória, sobre Camilo Mortágua:

Figura 10 - Questão sobre Camilo Mortágua em simulado de pré-vestibular

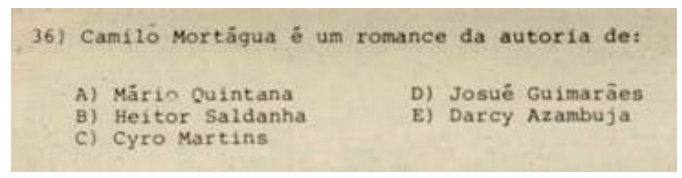

Fonte: Pioneiro (23/12/1981, p. 5).

Em janeiro de 1982, Josué Guimarães volta a figurar no simulado, em uma tabela organizada com os itens "autor", "obras" e "características". As obras destacadas são Depois do último trem, Camilo Mortágua, Os tambores silenciosos e A ferro e fogo. O conjunto da sua obra é caracterizado - mais uma vez, de forma muito simplória -, como: "A colonização alemã no RS. O retorno à condição humana, cheia de erros e fraquezas".

Outras referências ao autor, que chamam a atenção no Pioneiro, não dizem respeito, exatamente, aos campos do ensino de literatura e da crítica literária, nem dos eventos sobre literatura. Trata-se do gosto literário de candidatas à rainha da Festa da Uva, que tinham seus perfis culturais divulgados à comunidade, como requisito fundamental para pleitear a honraria. É assim que, em 06 de agosto de 1983, Sandra Galeão dos Santos, 17 anos, estudante do curso de Medicina da Universidade de Caxias do Sul, "garota de excelente formação cultural, destaca na literatura brasileira Mário de Andrade, Josué Guimarães, Graciliano Ramos e a sempre eterna poesia de Mario Quintana”.

Da mesma forma, Juliana Ainette Paglioli, 19 anos, estudante de Psicologia, pianista e que acredita que "um bom livro é uma ótima companhia" (PIONEIRO, 20/08/1983, p. 11), cita Moacyr Scliar, Josué Guimarães e Khalil Gibran como autores preferidos. Também Carla Barp Folchini, 21 anos, balconista e estudante de Biologia, destaca os romancistas Josué Guimarães, Hermann Hesse e J. M. Simmel (PIONEIRO, 03/11/1983, p. 25).

Finalmente, no apanhado desta seção, destacamos as referências ao autor de Camilo Mortágua em notícias sobre o município serrano de Canela. A primeira menção data de 11 de março de 1987, um ano após a morte do escritor. Com o título "Canela faz uma homenagem ao escritor Josué Guimarães”, a matéria tem o seguinte teor: 
Figura 11 - Homenagem a Josué Guimarães no município de Canela

(Da Sucursal de Gramado) - 0 Centro Cultural de Canela irá receber, em breve, a sala Josué Guimarães, que entra em funcionamento a partir de 23 de março, data do aniversário de morte do escritor.

A sala contará com diversos pertences, entre eles: toda a coleção com
25 livros publicados, uma máquina de escrever, uma escrivaninha, alguns quadros pintados por Josué, além de originais de alguns livros.

Josué Guimarães, filho de ferroviário e natural de São Jerônimo esteve em Canela em $1^{\circ}$ de janeiro de 1945 , por ocasião da emancipação do municí- pio, como jornalista do Diário de Notícias e, desde então, passou a gostar muito da cidade.

Participam do projeto a prefeitura de Canela, através da Secretaria de Turismo; a esposa do escritor, Nydia Guimarães; e a L\&PM Editora, que publicou os últimos livros de Josué.

Fonte: Pioneiro (11/03/1987, p. 13).

Nos anos seguintes, são noticiados outros eventos envolvendo o nome do escritor em Canela, e o principal deles é a Feira do Livro, que passa a receber o seu nome na segunda edição, em 1989, assim como a Casa de Cultura local. A sequência de notícias ao longo da década seguinte mostra o empenho dos promotores culturais pela preservação da memória de Josué e o vigor que a cena literária daquele município assumiu com a vinculação direta a seu nome.

\section{Participação em eventos literários e acadêmicos}

A participação de Josué Guimarães em eventos literários de Caxias do Sul não parece ter sido prolífica, já que localizamos apenas duas notícias: a já mencionada sessão de lançamento de Camilo Mortágua, na Livraria do Maneco, em 1980, e a presença em um encontro de literatura na Livraria Coletânea, em maio de 1977, junto com Moacyr Scliar, no contexto do Programa de Integração Cultural de Caxias do Sul, promovido pela universidade local. No dia 21, nas páginas 18 e 34 do Pioneiro, Josué Guimarães e Moacyr Scliar, "dois famosos homens de letras gaúchos", são apresentados como primeiros frutos de um concurso literário promovido pela Editora Globo, em homenagem a Erico Verissimo: 
Figura 12 - Obras de Josué Guimarães e Moacyr Scliar em coletânea

\section{JOSUÉ GUIMARÃES E MOACYR SCLIAR NA COLETÃNEA}

Recentemente a Editora Globo lançou um concurso nacional de romance, em homenagem à memória do grande escritor gaúcho Erico Veríssimo, concurso este que deverá repetir-se a cada dois anos. Pois os primeiros frutos desse prêmio foram os livros "Os tambores Silenciosos", de Josué Guimaràes, e "O Ciclo das Ảguas", de Moacyr Scliar, autores já consagrados como mestres incontestes da novelística brasileira.

$E$, na tentativa de proporcionar sempre e cada vez mais ao público leitor caxiense contatos com escritores do mais alto prestigio literário, a Livraria Coletânea estará trazendo, no próximo fim de semana, esses dois famosos homens de letras gaúchos. Josué Guimarães, além do livro premiado, tem outros livros publicados, como "Depois do Ültimo Trem", "A Ferro e Fogo - Tempo de Solidão", "A Ferro e Fogo Tempo de Guerra” e, em breve, esiara circulando em todo o Brasil outro titulo que completará a trilogia "A Ferro e Fogo". De Moacyr Scliar foram publicados: "O Exército de um Homem Só", "Carnaval dos Animais", "A Guerra no Bom Fim" e o premiado "O Ciclo das Águas”. Esta promoção da Coletânea e outras que serão feitas durante o ano em curso está inserida no Programa de Integraçào Cultural de Caxias do Sul, em comemoração aos dez anos de aniversário da nossa Universidade, juntament ? com outras entidades culturais, que estão trazendo a Caxias do Sul artistas do mais alto nivel cultural nos campos da Literatura, Cinema, Teatro, Música e Exposições de Arte. A programação da Coletânea para o fim de semana que vem é a seguinte: dia 27 , sextafeira, a partir das 18 horas, autógrafos na Livraria. No sábado, dia 28 , às nove horas, palestras sobre Literatura, com debates, no Clube Juvenil.

Fonte: Pioneiro (21/05/1977, p. 34). 
A propósito dessa passagem pela cidade, o Jornal de Caxias conversou com o escritor e trouxe a público, em 28 de maio de 1977, uma das mais belas entrevistas veiculadas na mídia impressa local, intitulada "O drama, a tragédia, a vida e a literatura que realiza diariamente Josué Guimarães”. O autor fala sobre a publicação do seu primeiro livro, Os ladrões (1970), a diferença entre escrever conto e romance, a atuação jornalística, a profissão de escritor e a censura. A respeito desse último tema, Josué é taxativo:

Se todo o escritor, se todo o jornalista se conscientizar de que a luta principal é pela liberdade, pelo direito de se discutir, apontar os erros, soluções de problemas do povo brasileiro, acesso à riqueza, à produção, à sociedade em si, humana, isto é uma luta de cabeça erguida, sempre, sem nenhum temor. Se vier temor, não é ruim a punição para nós, mas para quem a exerce. Digam o que disserem, pressionem o que pressionarem, não vou calar, vou continuar escrevendo meus livros e botando neles o que acho que tenho que botar [...] (JORNAL DE CAXIAS, 28/05/1977, p. 33).

Já no final da década de 1980 , o Pioneiro noticiou um evento na Universidade de Caxias do Sul, intitulado "Imigração e literatura no Rio Grande do Sul”, promovido pelo Departamento de Letras e Comunicação. Com a presença de pesquisadores importantes, como Regina Zilberman, Maria da Glória Bordini, Lígia Militz da Costa e Volnyr Santos, o seminário tratou da obra de autores que abordam alguns dos movimentos imigratórios no Estado: o Grupo Matrícula e a imigração italiana; Josué Guimarães e a imigração alemã; Moacyr Scliar e a imigração judaica; Aldyr Garcia Schlee e Sérgio Faraco e as imigrações portuguesa e castelhana. Entre os escritores presentes, são listados José Clemente Pozenato, Jayme Paviani, Ary Trentin e Oscar Bertholdo (os quatro em mesa-redonda), Charles Kiefer (como palestrante), Aldyr Garcia Schlee (como debatedor) e Moacyr Scliar (como debatedor). ${ }^{6}$

Um aspecto que fica patente em ambos os eventos é a atuação da Universidade na promoção e na divulgação de autores e obras. $\mathrm{O}$ meio acadêmico, tal como outras instituições, é uma instância importante de legitimação da literatura, porque costuma abrigar especialistas do campo literário que assumem a tarefa de sistematizar, de modo científico, um conhecimento sobre a literatura. No caso de Josué Guimarães, em função de $A$ ferro e fogo, ele foi filiado pelos pesquisadores ao tema da imigração alemã no Rio Grande do Sul - um lugar que até hoje ocupa com destaque.

\section{Josué Guimarães e José Clemente Pozenato}

A perspectiva assumida neste artigo, de investigar a presença de Josué Guimarães na imprensa de Caxias do Sul, de modo a discutir influxo da literatura suprarregio- 
nal no sistema literário local, não poderia estar completa sem que fizéssemos menção a uma entrevista do escritor José Clemente Pozenato ao jornal Pioneiro, em 1976, e a uma reportagem sobre o autor no Jornal de Caxias, dez anos depois.

Estreando na literatura em 1967, em uma antologia poética do grupo Reunião, Pozenato dedicou-se exclusivamente à poesia até 1985, quando vieram a público a novela $O$ caso do martelo e o romance $O$ quatrilho, o qual integraria a trilogia da imigração italiana, juntamente $\operatorname{com} A$ Cocanha (2000) e A Babilônia (2006). O autor é conhecido por ambientar as suas narrativas na região da Serra Gaúcha e, nessa trilogia, problematizar a imigração italiana no Rio Grande do Sul, entre as décadas de 1880 e 1930, de forma crítica e sem aparente ufanismo.

$\mathrm{Na}$ referida entrevista de 1976, indagado sobre "o que está melhor na região, a ficção ou a poesia?”, Pozenato responde:

Em termos quantitativos, e mesmo de repercussão para fora da nossa cerca, a poesia vai melhor. Temos Oscar Bertholdo, um nome que começa a ter projeção nacional, Jayme Paviani, Ary Trentim, além dos inéditos, todos eles produzindo poesia de primeira qualidade. Já na ficção o panorama não é tão animador, apesar de termos bons contistas. O que parece estar faltando é uma saga da imigração italiana, uma obra que apanhe num painel todo o significado histórico, cultural e mesmo mítico desta região. O lugar está vazio. Basta aparecer alguém de fôlego para fazer algo semelhante ao que está fazendo Josué Guimarães com relação à colonização alemã. (PIONEIRO, 20/11/1976, p. 8).
Nessa época, Josué Guimarães já havia publicado os dois primeiros volumes de A ferro e fogo e gozava de grande prestígio no meio jornalístico e literário. Pozenato, por sua vez, era um desconhecido poeta e professor de literatura da Universidade de Caxias do Sul, com atuação ainda restrita ao sistema literário local. Mas foi na senda aberta por Josué Guimarães em relação à imigração alemã no Rio Grande do Sul que Pozenato ("alguém de fôlego") apareceu, na década seguinte, "para fazer algo semelhante" sobre a imigração italiana.

Outra evidência da suposta inspiração de Pozenato em Josué Guimarães está registrada no Jornal de Caxias, em matéria de página inteira sobre o autor do recém-lançado romance $O$ quatrilho (1985). A certa altura, o articulista escreve: "Pozenato nos dizia que o aprendizado se faz com outros romances, com muita leitura. Machado de Assis, Mário Vargas Llosa são para ele os mais fortes. Josué Guimarães, Erico Verissimo e Clarice Lispector lhe dizem muito" (JORNAL DE CAXIAS, 26/05/1986, p. 16). ${ }^{7}$

\section{Considerações finais}

A presença constante do nome de Josué Guimarães na imprensa escrita de Caxias do Sul é inconteste. O material analisado - notícias de publicação de livros, simulados de vestibular, eventos acadêmicos, listas de autores mais vendi- 
dos, depoimentos de leitores, entrevistas e homenagens - possibilita afirmar que $o$ autor contribuiu, de forma indireta, para a consolidação do sistema literário da Serra Gaúcha, seja na formação de leitores, seja como inspiração para outros escritores.

Embora não seja possível utilizar uma métrica confiável para quantificar a influência do autor, não há dúvidas de que, no conjunto, o saldo é positivo. Isso porque os sistemas literários, ao se relacionarem uns com os outros, lançam mão de um conjunto de elementos de natureza sociocultural, tais como eventos, livrarias, meios de comunicação e instituições de fomento ao livro e à leitura, para estabelecer intercâmbios e influxos.

Na perspectiva do que propõe Stüben (2013), podemos afirmar que a influência de Josué Guimarães sobre a literatura da Serra Gaúcha não se deu por outra forma, que não a da disseminação da sua obra na região e do seu consequente efeito sobre o público, a crítica literária e outros autores. Quando, a partir de 1970, o conhecido jornalista começa a publicar suas obras literárias, a recepção entre os leitores serranos é muito veloz, a ponto de, em 1976 e 1977, ser citado, respectivamente, pelos poetas José Clemente Pozenato e Ary Trentin ${ }^{8}$ e, em 1978, figurar entre os mais vendidos da IV Feira do Livro de Caxias do Sul. ${ }^{9} \mathrm{Na}$ década seguinte, essa recepção expande-se ainda mais entre o público local, integrando-se às preferências literárias de candidatas à Festa da Uva, aos concursos vestibulares e se tornando um ícone da feira do livro de Canela.

\section{News by D. Xicote: the presence of Josué Guimarães in the literary system of Serra Gaúcha}

\section{Abstract}

In this article, we investigate the presence of Josué Guimarães in the written press of Caxias do Sul, between the 1950s and $1980 \mathrm{~s}$, in order to reflect on the influence of supraregional literature in the formation and consolidation of the literary system in Serra Gaúcha. The focus is on the newspapers A Época, Pioneiro, Diário do Nordeste and Jornal de Caxias, which mention the writer in interviews, social columns, lists of best-selling works, exam simulations and news about book publishing. The existence of columns signed by the pseudonym D. Xicote in two of these periodicals in the early 1950 s is particularly noteworthy.

Keywords: Josué Guimarães; D. Xicote; regional press; literary system of Serra Gaúcha.

\section{Notas}

1 Trabalho intitulado "Literatura e política: os poemas de Cyro de Lavra Pinto no Jornal Pioneiro", apresentado e premiado como um dos cinco melhores trabalhos na área de Ciências Humanas no XXVI Encontro de Jovens Pesquisadores e VIII Mostra Acadêmica de Inovação e Tecnologia da Universidade de Caxias do Sul em 2018. 
2 De acordo com Reis, Josué Guimarães criou o pseudônimo em 1944, quando teve uma coluna intitulada "Diário de Porto Alegre", no jornal Diário de Notícias.

3 Não pudemos apurar, no entanto, se o conteúdo era produzido exclusivamente para o Diário do Nordeste, ou, como era comum, replicado de outros jornais da época.

4 O Diário do Nordeste encerrou suas atividades em 1954, e A Época, em 1958.

5 A ideia de lugar de memória diz respeito ao fato de se fazerem homenagens a uma figura pública com a vinculação do seu nome a logradouros, prédios públicos, eventos etc. Ver, nesse sentido, o texto ARENDT, João Claudio. No rastro do Boi Barroso: literatura regional e lugares de memória. In: NUÑEZ, Carlinda Fragale Pate; SALES, Germana; RODRIGUES, Rauer Ribeiro; SOUZA, Roberto Acízelo de; BARBOSA, Socorro de F. P. (org.). História da literatura: práticas analíticas. Rio de Janeiro: Makunaima, 2012. v. 2. p. 101-123.

6 Josué Guimarães, falecido em 1986, não participou. Mesmo assim, esteve presente no evento em razão do destaque dado à sua obra no eixo temático da imigração alemã.

7 As possíveis ressonâncias da trilogia inacabada de Josué Guimarães na trilogia de José Clemente Pozenato ainda não foram investigadas.

8 Em entrevista concedida ao Jornal de Caxias, em 7 de maio de 1977, o poeta Ary Trentin também cita Josué Guimarães entre suas preferências literárias nacionais, ao lado de Machado de Assis, Guimarães Rosa, João Cabral, Drummond e Dalton Trevisan.

9 Uma reportagem do Jornal de Caxias (08/10/1977, p. 16), por ocasião dessa edição da Feira, trouxe a informação de que "Graciliano Ramos tem vendido bem, mas sem ultrapassar Josué Guimarães com seus Tambores silenciosos. A grande decepção, em todas as barracas, é a venda de autores locais, embora os preços sejam acessíveis".

\section{Referências}

A ÉPOCA. Comentário de D. Xicote. Caxias do Sul, 25 fev. 1950. Disponível em: https:// bityli.com/FPD5j. Acesso em: 26 jul. 2021.

CECCHIN, Aline Brustulin. Poetas em "reunião": o Grupo Matrícula e a consolidação de um sistema literário regional na Serra Gaúcha. Orientador: João Claudio Arendt. 2014. 140 f. Dissertação (Mestrado em Letras e Cultura Regional) - Universidade de Caxias do Sul, Caxias do Sul, 2014. Disponível em: https://repositorio.ucs.br/handle/11338/849. Acesso em: 22 jul. 2021.

CLEMENTE, Elvo. Josué Guimarães: uma vida plurifacetada. In: REMÉDIOS, Maria Luiza (org.) Josué Guimarães: o autor e sua ficção. Porto Alegre: EDIPUCRS; Editora da Universidade (UFRGS), 1997.

DIÁRIO DO NORDESTE. Convite. Caxias do Sul, 20 ago. 1952. Disponível em: https:// bityli.com/PEuFL. Acesso em: 20 jul. 2021.

DIÁRIO DO NORDESTE. Rainha Bila Vial. Caxias do Sul, 18 dez. 1951. Disponível em: https://bityli.com/M0R4z. Acesso em: 20 jul. 2021.

DIÁRIO DO NORDESTE. Solenemente instalado um aparelho teletipo na agência local do D.C.T. Caxias do Sul, 26 jun. 1951. Disponível em: https://bityli.com/fk0i1. Acesso em: 20 jul. 2021.

ARDELIN, Mário. Seleções do Dr. Moenda. Pioneiro, Caxias do Sul, 19 abr. 1952. Disponível em: https://bityli.com/xzZYR. Acesso em: 21 jul. 2021.

GUIMARÃES, Josué. Comentários de Don Xicote. Diário do Nordeste, Caxias do Sul, 13 jun. 1953. Disponível em: https://bityli. com/3db5a. Acesso em: 21 jul. 2021.

GUIMARÃES, Josué. Comentários de Don Xicote. Diário do Nordeste, Caxias do Sul, 27 jun. 1953. Disponível em: https://bityli.com/ JkMmA. Acesso em: 21 jul. 2021.

JORNAL DE CAXIAS. Fernando Sabino. Caxias do Sul, 24 fev. 1979. Disponível em: https://bityli.com/AuXGA. Acesso em: 27 jul. 2021.

JORNAL DE CAXIAS. José Clemente Pozenato. Caxias do Sul, 25 maio 1986. Disponível em: https://bityli.com/3ipa2. Acesso em: 27 jul. 2021. 
JORNAL DE CAXIAS. Josué Guimarães vem lançar nesta terça "Camilo Mortágua". Caxias do Sul, 17 nov. 1980. Disponível em: https://bityli.com/Ux81G. Acesso em: 27 jul. 2021.

JORNAL DE CAXIAS. O drama, a tragédia, a vida e a literatura que realiza diariamente Josué Guimarães. Caxias do Sul, 28 maio 1977. Disponível em: https://bityli.com/5dAfj. Acesso em: 25 jul. 2021.

JORNAL DE CAXIAS. Para Ary Trentin, a poesia é uma forma de viver mais profundamente a realidade. Caxias do Sul, 7 maio 1977. Disponível em: https://bityli.com/Es1pj. Acesso em: 25 jul. 2021.

JORNAL DE CAXIAS. Uma feira para todos os gostos, todos os bolsos, até segunda... Caxias do Sul, 8 out. 1977. Disponível em: https:// bityli.com/Bqf29. Acesso em 26 jul. 2021.

PIONEIRO. A pedido. Caxias do Sul, 19 ago. 1950. Disponível em: https://bityli. com/1uHkC. Acesso em: 21 jul. 2021.

PIONEIRO. Canela faz uma homenagem ao escritor Josué Guimarães. Caxias do Sul, 11 mar. 1987. Disponível em: https://bityli.com/ UO6sx Acesso em: 23 jul. 2021.

PIONEIRO. Clemente Pozenato fala de literatura. Caxias do Sul, 20 nov. 1976. Disponível em: https://bityli.com/n5uKm. Acesso em: 24 jul. 2021.

PIONEIRO. Comercial Pratavieira Alberti S.A. Caxias do Sul, 3 nov. 1983. Disponível em: https://bityli.com/K29j0. Acesso em: 23 jul. 2021.

PIONEIRO. Conferência Jorge Amado. Caxias do Sul, 23 ago. 1952. Disponível em: https://bityli.com/EZ9ad. Acesso em: 20 jul. 2021.

PIONEIRO. Cursão vai com a bela Sandra. Caxias do Sul, 6 ago. 1983. Disponível em: https://bityli.com/BHjzb. Acesso em: 23 jul. 2021.
PIONEIRO. Dona Anja: Josué Guimarães: Editora LPM: 201 páginas. Caxias do Sul, 11 nov. 1978. Disponível em: https://bityli.com/ WZORU. Acesso em: 21 jul. 2021.

PIONEIRO. Josué Guimarães e Moacyr Scliar na coletânea. Caxias do Sul, 21 maio 1977. Disponível em: https://bityli.com/ WQxQ3. Acesso em: 24 jul. 2021.

PIONEIRO. Josué, um político: Camilo, um partidário. Caxias do Sul, 11 nov. 1980. Disponível em: https://bityli.com/GbiOL. Acesso em: 22 jul. 2021.

PIONEIRO. Juliana em busca do título. Caxias do Sul, 20 ago. 1983. Disponível em: https://bityli.com/rOWQR. Acesso em: 21 jul. 2021.

PIONEIRO. Mais um estabelecimento de ensino em nossa cidade. Caxias do Sul, 28 maio 1955. Disponível em: https://bityli.com/ K19Xy. Acesso em: 20 jul. 2021.

PIONEIRO. O cavalo cego: Josué Guimarães: Editora Globo: 154 páginas. Caxias do Sul, 24 nov. 1979. Disponível em: https://bityli.com/ ZzVwf. Acesso em: 26 jul. 2021.

PIONEIRO. Prova de comunicação e expressão. Caxias do Sul, 23 dez. 1981. Disponível em: https://bityli.com/BMabo. Acesso em: 22 jul. 2021.

REIS, Paulo Roberto de Oliveira. Phileas Fogg: Josué Guimarães viaja na crônica em jornal. 1999. Dissertação (Mestrado em Letras) - Pontifícia Universidade Católica do Rio Grande do Sul, Porto Alegre, 1999.

STÜBEN, Jens. Literatura regional e literatura na região. In: ARENDT, João Claudio; NEUMANN, Gerson Roberto. Regionalismus - Regionalismos. Caxias do Sul: EDUCS, 2013. p. 37-73. 